\title{
Comparative analysis of RCAS1 level in neoplasms and placenta ${ }^{\star}$
}

\author{
Lukasz Wicherek $^{1 凶}$, Magdalena Dutsch ${ }^{2}$, Pawel Mak ${ }^{3}$, Marek Klimek ${ }^{1}$, \\ Jacek Skladzien ${ }^{2}$ and Adam Dubin ${ }^{3}$
}

Departments of ${ }^{1}$ Gynecology and Infertility Clinic, ${ }^{2}$ Otolaryngology,

${ }^{3}$ Faculty of Biotechnology, Jagiellonian University, Kraków, Poland

Received: 30 May, 2003; revised: 22 October; accepted: 28 November, 2003

Key words: apoptotic cell death, EBAG9, fetal rejection, immune escape, RCAS1

\begin{abstract}
The tumor associated antigen RCAS1 (receptor-binding cancer antigen expressed on SiSo cells) expressed with high frequency in various cancer and trophoblast cells, inhibits growth of estrogen receptor-expressing cells and induces apoptosis. Because previous reports demonstrated RCAS1 presence only by non-quantitative immunocytochemistry methods, we decided to use a Western blotting with anti-RCAS1 monoclonal antibodies for estimation of the relative content of the tumor-associated antigen. One hundred tissue samples were assayed (neoplasms, chronic inflammatory diseases, healthy tissues, trophoblasts and placentas at term). RCAS1 was present in all neoplastic, placental and trophoblast tissue samples and its level in malignant samples was statistically significantly higher than in benign neoplasms. The amount of RCAS1 in chronic inflammations was also significantly increased in immune mediated diseases, like allergic nasal polyps and sarcoidosis. The RCAS1 protein was not revealed in healthy mucous membrane and in muscle tissues. The presented results suggest that RCAS1 might play an important role in tumor escape from host immunological surveillance and carry weight in the down regulation of the maternal immune response, thereby maintaining pregnancy.
\end{abstract}

The tumor associated antigen RCAS1/ EBAG9 (receptor-binding cancer antigen expressed on SiSo cells/estrogen receptor-binding fragment associated antigen 9) is a type II membrane protein (Watanabe et al., 1998; Nakashima et al.,1999), expressed on human cancer cells of uterus as well as digestive and respiratory tract (Sonoda et al., 2000; Tsune-

\footnotetext{
ॠ Presented at the XXX Winter School of Faculty of Biotechnology, Jagiellonian University, Kościelisko, Poland, 28th February-4th March, 2003.

${ }^{凶}$ Lukasz Wicherek, Department of Gynecology and Infertility Clinic, Jagiellonian University, M. Kopernika 23, 31-501 Kraków, Poland; tel.: (48 12) 424 8529, fax (48 12) 424 8586; e-mail: mowicher@cyf-kr.edu.pl
}

Abbreviations: EBAG9, estrogen receptor-binding fragment associated antigen 9; RCAS1, receptor-binding cancer antigen expressed on SiSo cells. 
izumi et al., 2001; Oshikiri et al., 2001; Suzuki et al., 2001; Noguchi et al., 2001; Umeoka et al., 2001). The RCAS1 is also present in uterine gland, extra-villous cytotrophoblasts, erythroid progenitor cells (Ohshima et al., 2001a), immune-mediated diseases (Enjoji et al., 2002), trophoblast cells (Ohshima et al., 2001b) and in placenta at term (Wicherek et al., 2003a). The RCAS1 protein is a homodimer of 213 amino acid-long monomers, each with an N-terminal transmembrane segment and a coiled-coil structure in the C-terminal portion. Its expression is estrogen receptor dependent. Similarly as other type II membrane proteins RCAS1 can also be secreted in a soluble form, which was confirmed in cancer cell culture (Nakashima et al., 1999). In Western blotting technique with monoclonal anti- RCAS1 antibodies the membrane-bound and soluble forms of protein localizes in 32 and $25 \mathrm{kDa}$ bands, respectively (Tsuchiya et al., 2001; Engelsberg et al., 2003). The RCAS1 protein acts as a ligand for a putative receptor present on various human cells including normal peripheral lymphocytes such as T, B and NK (natural killer) cells, inhibits growth of receptor expressing cells in vitro and in vivo and induces apoptotic cell death through activation of caspase 3 and collapse of mitochondrial transmembrane potential (Matsushima et al., 2001).

The expression of RCAS1/EBAG9 in cancer cells helps to avoid immune recognition and evade immune surveillance. Similarly, presence of this protein in uterine glands and cytotrophoblasts is reflection of its role in the down regulation of the maternal immune response (Ohshima et al., 2001b).

The aim of our research was to compare the presence of RCAS1 at the protein level in neoplasms and placenta, i.e. in tissue samples derived from head and neck pathologies like cancers, immune-mediated diseases and blood serum samples, ovarian cancer, skin cancer and in samples of placenta at term. The RCAS1 level was determined using a Western blotting method, in contrast to previ- ous reports (Ohshima et al., 2001b), where the presence of RCAS1 was demonstrated only by immunohistochemistry (in trophoblast and in neoplastic tissue samples). In this report we present also evidence for the existence of soluble RCAS1 form in blood serum.

\section{MATERIALS AND METHODS}

Chemicals. If not stated otherwise, all chemicals used were from Sigma, U.S.A.

Tissue samples. Tissue samples were divided into neoplasmatic and non-neoplasmatic ones. RCAS1 content was estimated in 51 placental tissue samples, 22 neoplasms (ovarian, head and neck, skin) and 16 samples derived from chronic inflammatory diseases of the head and neck. Nine samples were obtained from healthy tissue. We also analyzed two blood serum samples, one derived from patient with benign neoplasm, the other from a patient with chronic inflammatory disease. Tissue samples were obtained from the Otolaryngology Department, Department of Gynecology and Infertility Clinic of Jagiellonian University during routine surgery and after parturition at term or Cesarean section. In all cases patients' consent was obtained. The samples were histopathologically verified by the Anatomy and Pathology Department of Jagiellonian University.

Preparation of tissue extracts. Tissue samples (average dimensions $0.5 \times 0.5 \times 0.5$ $\mathrm{cm}$ ) obtained during surgery were immediately mixed with Complete Proteinase Inhibitor Cocktail (Roche, Germany) and homogenized in ice-bath in a glass-glass Potter-Elvejhem homogenizer. The resulting suspensions were mixed with equal volume of SDS-PAGE sample lysis buffer (4\% SDS, 20\% glycerol, $125 \mathrm{mM}$ Tris/HCl, $\mathrm{pH}$ 6.8) and boiled in a water bath for $5 \mathrm{~min}$. Chilled samples were then spun down at $16000 \times \boldsymbol{g}$ for $15 \mathrm{~min}$ at room temperature and the supernatants were used for further analysis. Blood serum was pre- 
pared by centrifugation of heparinised blood at $2000 \times \boldsymbol{g}$ for $10 \mathrm{~min}$, second centrifugation of the obtained supernatant at $16000 \times \boldsymbol{g}$ for 10 min and mixing with proteinase inhibitor cocktail, equal volume of SDS-PAGE sample lysis buffer and boiling as above.

Western blotting. Total protein content in the obtained supernatants was measured using BCA assay kit and different sample volumes (usually in the range of $2-10 \mu \mathrm{l}$ ) equivalent to $50 \mu \mathrm{g}$ of total protein were then loaded on SDS/PAGE Tris/Tricine gels (Shagger \& von Jagow, 1987). Prestained broad range molecular mass protein mix standard (Bio Rad, U.S.A.) was used in marker lane. After electrophoresis the gels were electrotransferred on Immobilon-P polyvinylidene difluoride (PVDF) $0.45 \mu \mathrm{m}$ membrane (Millipore, U.S.A.) in a buffer containing $10 \mathrm{mM}$ 3-(cyclohexyloamino)-1-propanesulfonic acid (CAPS), pH 11, supplemented with $10 \%$ methanol. The obtained membrane blots were blocked by overnight gentle agitation in $5 \%$ bovine serum albumin in TST buffer $(0.01 \mathrm{M}$ Tris/HCl, $\mathrm{pH}$ $7.4,0.9 \% \mathrm{NaCl}, 0.5 \%$ Tween-20). After discarding the albumin solution the membranes were agitated for $2 \mathrm{hr}$ in a 1:4000 dilution of mouse monoclonal anti-RCAS1 MoAb 22-1-1 IgM-class antibody (Medical and Biological Laboratories, Japan) in TST buffer. The membranes were then subjected to cycles of 5-min washing in TST buffer and immersed in a 1:2000 dilution of biotinylated anti-mouse IgM $\mu$-chain specific antibodies for $2 \mathrm{hr}$ with agitation. After four cycles of washing the membranes were soaked for $2 \mathrm{hr}$ in a 1:2000 dilution of ExtrAvidin-alkaline phosphatase conjugate and finally washed two times in TST buffer and two times in TST without Tween-20. The color was developed using Fast Red TR/Naphtol AS-MX tablet set. Sufficient band intensity was usually obtained after $5 \mathrm{~min}$ of developing. The immunoblotts were then rinsed with water and air-dried. The whole procedure was conducted at room temperature.
Computer-aided image analysis. Fluor-S MultiImager (BioRad, U.S.A.) was used to scan the immunoblot membranes and the computer program QuantityOne (BioRad, U.S.A.) was used to quantitate band intensities. All calculations were performed for the soluble form of RCAS1 antigen having molecular mass of about $25 \mathrm{kDa}$. The intensities of this band were expressed in arbitrary relative units and one unit (U) was defined as the band intensity produced by the reference sample. This reference sample was randomly chosen but was the same on all blots and was applied always in the same amount. Because all immunoblots contained the same RCAS1 quantity standard and all lanes were loaded with the same amount of total protein $(50 \mu \mathrm{g})$ the determined values were highly repetitive and independent of experiment conditions. The result always shows the relative amount of RCAS1 $25 \mathrm{kDa}$ antigen in $50 \mu \mathrm{g}$ of total sample protein.

Statistical analysis. Statistical calculations were performed using Statistica computer program (StatSoft, Poland). Data series were tested using Student's $t$-test and assuming normal distribution.

\section{RESULTS AND DISCUSSION}

The monoclonal anti-RCAS1 antibodies in Western blotting technique allow to visualize the $32 \mathrm{kDa}$ band characteristic for the membrane-bound form of RACAS1 as well as 25 $\mathrm{kDa}$ band for soluble form (Nakashima et al., 1999; Tsuchiya et al., 2001; Engelsberg et al., 2003). The presented comparative data reflect level of the $25 \mathrm{kDa}$ form because of its common occurrence in the various tissue extracts. The presence of the RCAS1 protein was revealed in all neoplastic and placental samples examined and in $62.5 \%$ of chronic inflammations. The highest amount of RCAS1 among all the samples was found in trophoblast tissue (average relative amount 
Table 1. Relative amount of RCAS1 in various tissue samples.

\begin{tabular}{lcccc}
\hline Tissue & Neoplasm & Placenta & Chronic inflammation & Healthy tissue \\
\hline Number of samples & 22 & 51 & 12 & 9 \\
RCAS1 relative & $1.417 \pm 0.766$ & $0.849 \pm 0.605$ & $0.459 \pm 0.646$ & 0 \\
amount & (range $0.158-2.706)$ & (range 0.091-3.42) & (range 0-1.55) & \\
\hline
\end{tabular}

3.420). The RCAS1 content in neoplasms (squamous cell carcinoma of head and neck, basal cell carcinoma of skin, squamous cell carcinoma of skin, ovarian adenocarcinoma, inverted papilloma of nasal cavity, pleomorphic adenoma) was higher than in
The RCAS1 content in malignant neoplasms was statistically significantly higher than in benign neoplasms (Table 2). All immune mediated chronic inflammation samples contained RCAS1, but in inflammations based on other mechanisms (mainly bacterial) its level

Table 2. Comparison of relative RCAS1 content in malignant and benign neoplasms (statistically significant $P<0.05)$.

\begin{tabular}{|c|c|c|}
\hline Tissue & Malignant neoplasms & Benign neoplasms \\
\hline Number of samples & 19 & 3 \\
\hline RCAS1 relative amount & $\begin{array}{c}1.586 \pm 0.671 \\
\text { (range } 0.389-2.706)\end{array}$ & $\begin{array}{c}0.344 \pm 0.33 \\
\text { (range } 0.148-0.726 \text { ) }\end{array}$ \\
\hline$P$ & & \\
\hline
\end{tabular}

chronic inflammations (chronic sialoadenitis, neutrophilic nasal polyps, eosinophilic nasal polyps, sarcoidosis, reactive lymphadenitis). The highest amount of RCAS1 among the neoplastic tissue samples was observed in squamous cell carcinoma of palatine tonsil was significantly decreased. The average amounts and statistical correlations are presented in Table 3.

The RCAS1 protein was also found in two blood serum samples, one derived from a patient with benign neoplasm and the other

Table 3. Relative RCAS1 content in immune mediated diseases in comparison with other inflammations (statisticaly significant $P<0.05$ ).

\begin{tabular}{|c|c|c|}
\hline Tissue & Immune mediated inflammations & Other inflammations \\
\hline Number of samples & 6 & 6 \\
\hline RCAS1 relative amount & $\begin{array}{c}0.853 \pm 0.723 \\
\text { (range } 0.12-1.77 \text { ) }\end{array}$ & $\begin{array}{c}0.0646 \pm 0.154 \\
\text { (range } 0.009-0.379 \text { ) }\end{array}$ \\
\hline$P$ & \multicolumn{2}{|c|}{0.0259} \\
\hline
\end{tabular}

high grade (average relative amount 2.706). In tissue samples obtained from chronic inflammations the average amount of RCAS1 was 0.460 . We did not find RCAS 1 antigen in healthy tissue samples (mucose membrane of upper respiratory tract, muscle tissue, skin). These results are collected in Table 1. from a patient with chronic inflammatory disease. The relative amount of this soluble RCAS 1 form is presented in Table 4.

The distribution of RCAS1 in trophoblast, ovarian cancer and peritoneal metastases tissue samples derived from one pregnant woman is shown in Table 5. Hysterectomy 
was performed in 13th week of gestation, because of ovarian adenocarcinoma (GII).

Figure 1 demonstrates a typical immuno- quantitative form confirm previous reports about the possible role of RCAS1 in tumor escape from immune surveillance (Kubokawa et

Table 4. Comparison of relative amount of RCAS1 in blood serum and in pathologic tissues observed in two patients.

\begin{tabular}{lcc}
\hline \multicolumn{1}{c}{ Histopathological diagnosis } & $\begin{array}{c}\text { RCAS1 relative amount in blood } \\
\text { serum }\end{array}$ & $\begin{array}{c}\text { RCAS1 relative amount in tissue } \\
\text { sample }\end{array}$ \\
\hline $\begin{array}{l}\text { Pleomorphic adenoma of parotid } \\
\text { gland }\end{array}$ & 0.631 & 0.148 \\
$\begin{array}{l}\text { Chronic sialadenitis of } \\
\text { submandibular gland }\end{array}$ & 0.07 & 0 \\
\hline
\end{tabular}

blot. The membrane contains samples derived from placentas at term and samples from different head and neck tumors. Two main bands are visible, the $32 \mathrm{kDa}$ band of transmembrane protein and the $25 \mathrm{kDa}$ form of soluble RCAS1. The figure illustrates also that $25 \mathrm{kDa}$ antigen is present in all samples and is more convenient for use in comparative studies. It is also worth of noting that placenta at term samples contain additional 21 al., 2001). RCAS1 has been suggested to help neoplasm to avoid host immune recognition, helps to survive in blood vessels, lymph nodes and extra-cellular matrix (Kubokawa et al., 2001). We also identified RCAS1 protein in tissue samples with chronic inflammatory diseases, which were not pre-cancerous lesions. The amount of RCAS1 in chronic inflammations was significantly increased in immune mediated diseases, such as allergic nasal pol-

Table 5. Comparison of relative amount of RCAS1 in tissue samples derived from one pregnant women (uterus and ovary in 13th week of gestation with accompanying ovarian cancer).

\begin{tabular}{lc}
\hline Tissue samples & RCAS1 relative amount \\
\hline Shaggy chorion & 3.42 \\
Ovarian adenocarcinoma (GII) & 1.37 \\
Peritoneal metastases & 1.96 \\
\hline
\end{tabular}

$\mathrm{kDa}$ band. According to Winkler et al. (1999) we assume that this band corresponds to product of RCAS1 fragmentation during labor.

In our investigation we confirmed the presence of the RCAS1 protein in all neoplastic tissue samples and all placental samples (Table 1). The content of RCAS1 in malignant tissue samples was statistically significantly higher than in benign neoplasms (Table 2). The RCAS1 level was greater in peritoneal metastases than in primary ovarian cancer (Table 5). The RCAS1 expression correlated to tumor grading, lymph node metastases and short outcome (Oshikiri et al., 2001; Rousseau et al., 2002). The obtained results in yps and sarcoidosis (Table 3). Enjoji et al. (2002) have indicated that the RCAS1/ RCAS1-receptor system is probably engage in a defense against immune system attack.

RCAS1 was also found in a shaggy chorionic tissue sample. During the first trimester of gestation the trophoblast cells grow invasively into decidua, which is a physiological process, similar to previously described neoplastic invasiveness. RCAS1 is expressed in extra villous and villous cytotrofoblast and in histiocytes in chorionic villi (Ohshima et al., 2001b). The expression of RCAS1 in uterine glands and cytotrophoblast plays a role in the down regulation of the maternal immune response. We can therefore hypothesize that 
RCAS1 may participate in inhibition of maternal immune attack (Wicherek et al., 2003b).

We also compared the pattern of RCAS1 bands derived from patients with squamous cell carcinoma of head and neck with that derived from placenta at term. Two main bands were identified: $32 \mathrm{kDa}$ and $25 \mathrm{kDa}$. Neoplas- and therefore the results presented in Table 4, contain data from single medical case.

The RCAS1 presence in trophoblast and neoplastic tissue samples has been reported previously, but the analysis was only done by non-quantitative immunohistochemistry techniques. Our relative determinations of RCAS1 level confirmed presence of this pro-

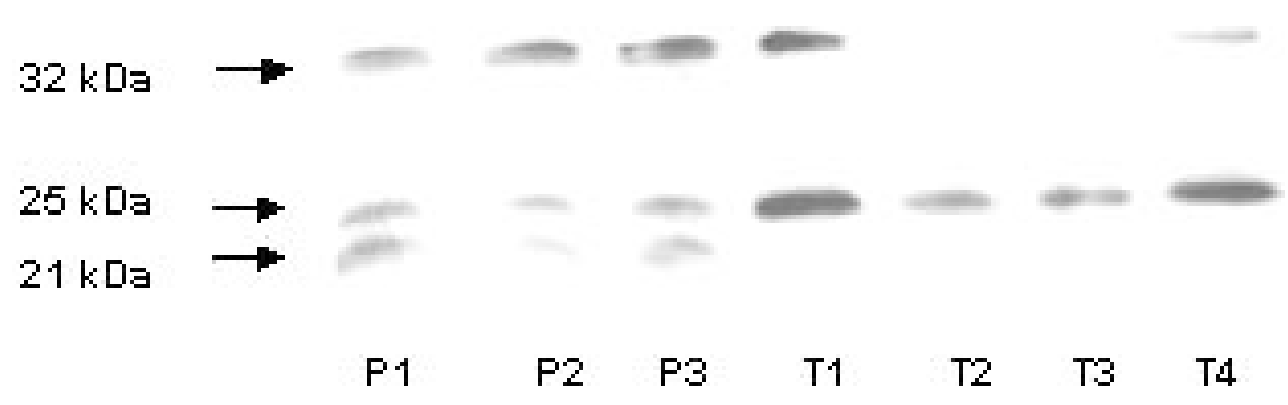

Figure 1. A comparison of RCAS1 band patterns in placenta at term as well as in head and neck carcinoma tissues.

P1-P3 represent placentas while T1-T4 represent 4 different carcinomas. T, transmembrane $32 \mathrm{kDa}$ form of RCAS1; S, $25 \mathrm{kDa}$ soluble form RCAS1; F, $21 \mathrm{kDa}$ product of possible RCAS1 fragmentation during labor.

tic tissue is characterized by the presence of both bands, with prevalence of $25 \mathrm{kDa}$ band, similarly to the shaggy chorionic tissue samples. The placental samples derived during parturition (after 24th week of gestation), contain both bands ( $25 \mathrm{kDa}$ and $32 \mathrm{kDa}$ ), but the $25 \mathrm{kDa}$ band in some cases is accompanied by a $21 \mathrm{kDa}$ band. As was suggested earlier, the presence of this degraded low-molecular form may be connected with the increase of matrix metaloproteinase (MMP) activity during the labor (Winkler et al., 1999).

As was shown earlier (Nakashima et al., 1999; Sonoda et al., 2000) the neoplastic cells are able in vitro to secrete the RCAS 1 antigen into the extracelluar matrix. This soluble RCAS1 form induced apoptosis in cultures of receptor-positive cells (e.g. leukemia cells K562) and this activity was reduced after absorption with Mab 22-1-1 antibody. We identified the $25 \mathrm{kDa}$ RCAS1 soluble form in blood serum samples (Table 4). Unfortunately, we were not able to collect more samples in clinic tein in placenta and neoplasms and demonstrated that the level of this antigen in specific tissues is related to tumor grading and immunological status. RCAS1 is a protein, which seems to play an important role in tumor escape from host immunological surveillance, developing of metastases and in the down regulation of the maternal immune response. We also suspect, that RCAS1 may play a role in labor initiation. Further investigations are underway.

We wish to thank Professor R. Klimek and Professor H. Nakano for advice and helpful discussions. We would also like to thank Professor J. Stachura for the support and help.

\section{R E F E R E N C E S}

Engelsberg A, Hermosilla R, Karsten U, Schulein R, Dorken B, Rehm A. (2003) The Golgi protein RCAS1 controls cell surface ex- 
pression of tumor-associated O-linked glycan antigens. J Biol Chem.; 278: 22998-3007.

Enjoji M, Nakashima M, Nishi H, Choi I, Oimomi H, Sugimoto R, Kotoh K, Taguchi K, Nakamuta M, Nawata H, Watanabe T. (2002) The tumor-associated antigen, RCAS1, can be expressed in immune-mediated diseases as well as in carcinomas of biliary tract. J Hepatol.; 36: 786-92.

Kubokawa M, Nakashima M, Yao T, Ito KI, Harada N, Nawata H, Watanabe T. (2001) Aberrant intracellular localization of RCAS1 is associated with tumor progression of gastric cancer. Int J Oncol.; 19: 695-700.

Matsushima T, Nakashima M, Oshima K, Abe Y, Nishimura J, Nawata H, Watanabe T, Muta K. (2001) Receptor binding cancer antigen expressed on SiSo cells, a novel regulator of apoptosis of erythroid progenitor cells. Blood.; 98: 313-21.

Nakashima M, Sonoda K, Watanabe T. (1999) Inhibition of cell growth and induction of apoptotic cell death by the human tumor-associated antigen RCAS1. Nat Med.; 5: 938-42.

Ohshima K, Muta K, Nakashima M, Haraoka S, Tutiya T, Suzumiya J, Kawasaki C, Watanabe T, Kikuchi M. (2001a) Expression of human tumor-associated antigen RCAS1 in Reed-Sternberg cells in association with Epstein-Barr virus infection: a potential mechanism of immune evasion. Int $J$ Cancer.; 93: 91-6.

Ohshima K, Nakashima M, Sonoda K, Kikuchi M, Watanabe T. (2001b) Expression of RCAS1 and FasL in human trophoblasts and uterine glands during pregnancy: the possible role in immune privilege. Clin Exp Immunol.; 123: 481-6.

Oshikiri T, Hida Y, Miyamoto M, Hashida H, Katoh K, Suzuoki M, Nakakubo Y, Hiraoka K, Shinohara T, Itoh T, Kondo S, Katoh H. (2001) RCAS1 as a tumour progression marker: an independent negative prognostic factor in gallbladder cancer. $\mathrm{Br} \mathrm{J}$ Cancer.; 85: $1922-7$.

Rousseau J, Tetu B, Caron D, Malenfant P, Cattaruzzi P, Audette M, Doillon C,
Tremblay JP, Guerette B. (2002) RCAS1 is associated with ductal breast cancer progression. Biochem Biophys Res Commun.; 293: 1544-9.

Schagger H, von Jagow G. (1987) Tricine-sodium dodecyl sulphate polyacrylamide gel electrophoresis for separation of proteins in the range from $1 \mathrm{kDa}$ to $100 \mathrm{kDa}$. Anal Biochem.; 166: 368-79.

Sonoda K, Kaku T, Hirakawa T, Kobayashi H, Amada S, Sakai K, Nakashima M, Watanabe T, Nakano H. (2000) The clinical significance of tumor-associated antigen RCAS1 expression in the normal, hyperplastic, and malignant uterine endometrium. Gynecol Oncol.;

79: 424-9.

Suzuki T, Inoue S, Kawabata W, Akahira J, Moriya T, Tsuchiya F, Ogawa S, Muramatsu M, Sasano H. (2001) EBAG9/RCAS1 in human breast carcinoma: a possible factor in endocrine-immune interactions. $\mathrm{Br} J$ Cancer.; 85: $1731-7$.

Tsuneizumi M, Emi M, Nagai H, Harada H, Sakamoto G, Kasumi F, Inoue S, Kazui T, Nakamura Y. (2001) Overrepresentation of the EBAG9 gene at 8q23 associated with early-stage breast cancers. Clin Cancer Res.; 11: $3526-32$.

Umeoka K, Sanno N, Oyama K, Tahara S, Kurotani R, Ikuyama S, Nakashima M, Watanabe T, Osamura RY, Teramoto A. (2001) Immunohistochemical analysis of RCAS1 in human pituitary adenomas. Mod Pathol.; 14: 1232-6.

Watanabe T, Inoue S, Hiroi H, Orimo A, Kawashima H, Muramatsu M. (1998) Isolation of estrogen-responsive genes with a $\mathrm{CpG}$ island library. Mol Cell Biol.; 18: 442-9.

Wicherek L, Dutsch M, Mak P, Klimek M. (2003a) The presence of RCAS1 in pregnant uterus with concomitant ovarian cancer. Ginekol Prakt.; 72: 8-10.

Wicherek L, Dutsch M, Mak P, Klimek M. (2003b) The presence of RCAS1/EBAG9 in placenta at term. Ginekol Prakt.; 74: 20-2.

Winkler M, Fischer DC, Ruck P, Marx T, Kaiserling A, Oberpichler A, Tshesche H, 
Rath W. (1999) Parturition at term: parallel increases of interleukin- 8 and proteinase concentrations and neutrophil count in the lower uterine segment. Hum Reprod.; 14: 1096-1110. 